\title{
Targeted Combination HIV Prevention Packages to Halt the Global HIV Epidemic
}

\section{Gita Ramjee* and Brodie Daniels}

HIV Prevention Research Unit, South African Medical Research Council, Durban, South Africa

\begin{abstract}
Thirty years after the discovery of HIV, the epidemic is still a major health concern with no cure in sight. Globally there are regions with concentrated epidemics where high risk groups drive the HIV incidence rates whereas regions with a generalized epidemic have the population at large at risk of HIV acquisition. Current HIV prevention efforts such as HIV testing and counseling, STI treatment and condom use have not been entirely successful. New biomedical interventions have recently shown to be efficacious in the prevention of HIV in specific populations. It is evident that, depending on the population groups driving the epidemic, countries need to take stock of their HIV epidemic and prepare an appropriate response using a combination of current and new biomedical HIV prevention interventions to minimize HIV incidence.
\end{abstract}

\section{Keywords: HIV; Prevention; Epidemiology}

Abbreviations: HIV: Human Immunodeficiency Virus; STIs: Sexually Transmitted Infections; MSM: Men that have Sex with Men; IDU's: Injecting Drug users; ART: Anti-Retroviral Therapy; RCTs: Randomized Control Trials; HCT: HIV Counselling and Testing; NSPs: Needle and Syringe Programs; OST: Opioid Substitution Therapy; MIRA: Methods for Improving Reproductive Health in Africa; HSV-2: Herpes Simplex Virus-2; HAART: Highly Active Antiretroviral Therapy; RT: Reverse Transcriptase; TDF: Tenofovir Disoproxil Fumarate; FTC: Emtricitabine; SIV/SHIV: Simian/Human Immunodeficiency Virus; PrEP: Pre-Exposure Prophylaxis; PIP: Partners In PrEP; VOICE: Vaginal and Oral Interventions to Curb the Epidemic; DSMB: Data Safety and Monitoring Board; PMTCT: Preventing Mother To Child Transmission; MMC: Male Medical Circumcision; FACTS: Follow-on African Consortium for Tenofovir Studies; SPP: Standard Prevention Package; TB: Tuberculosis; ARV: Antiretroviral; MARCH: Modeling And Reinforcement to Combat HIV/AIDS; AEs: Adverse Effects; MTSW: Male and Transgender Sex Workers

\section{Introduction}

Over 60 million men, women and children have been infected with the Human Immunodeficiency Virus (HIV) globally and over 25 million have died [1]. The global HIV epidemic peaked in 1999. Between then and 2009, the number of new infections decreased by $19 \%$. The current estimate is that there are approximately 34 million people living with HIV globally [2-4]. In 2010, approximately 2.7 million people became newly infected with HIV, one fifth less than in 1999 , where there were approximately 3.1 million new infections. There are approximately 15 million people living with HIV in low- and middle-income countries who require treatment, of which 6.6 million had access to treatment as of the end of 2010. The number of people receiving treatment globally has increased 13 -fold since 2004 . This increased access to treatment has resulted in a $19 \%$ decline in deaths among people living with HIV between 2004 and 2009 and the HIV incidence has fallen by more than $25 \%$ between 2001 and 2009 in 33 countries (22 of which are in sub-Saharan Africa). A combination of factors has caused this trend, including the natural course of epidemics and the effect of HIV and treatment prevention efforts [3-5].

A remarkable aspect of the spread of HIV is its heterogeneity across socially and geographically defined populations [6]. These variations cannot be explained by chronological differences in when HIV was first introduced into natural populations or regions. The spread is also characterized by sharp variations between socially defined groups (such as men that have sex with men (MSM) and injecting drug users (IDUs) [6]. Data also suggests an increased risk of HIV infection with episodic recreational drug or alcohol abuse. The probability of HIV acquisition is increased by: the population prevalence of HIV; concurrent sexual relationships; partner change; sexual practices; the presence of other sexually transmitted infections (STIs) and population mobility patterns for economic or other reasons [7].

The global pandemic follows two broad patterns, the first being a generalized epidemic with heterosexual transmission as the primary driver of HIV infection in the population. In these epidemics HIV is firmly established in the general population (the HIV prevalence in the general population or in pregnant women is above $1 \%$ ), regardless of the presence of sub-populations at high risk (e.g. sex workers) that may continue to contribute disproportionately to the spread of HIV. In countries with a generalized epidemic, the sexual networking is sufficient to prolong an epidemic independent of the high risk groups. When there is sufficient mixing of these high risk individuals with the general population, epidemiological 'bridging' may take place where the epidemic might become more generalized and increase swiftly [8-10]. HIV transmission in countries with generalized epidemics is linked to high levels of heterosexual partner turnover among men and women, having concurrent sexual relationships and unprotected sex $[7,10,11]$. While sub-Saharan Africa has a regional generalized epidemic, many regions with overall concentrated epidemics may have some countries where the epidemic is more generalized [12]. See below.

The second broad pattern of the HIV pandemic is concentrated epidemics where HIV disproportionately affects individuals with

*Corresponding author: Gita Ramjee, Director, HIV Prevention Research Unit, South African Medical Research Council, Durban, South Africa, Tel: +27 31242 3631; Fax: +27 31242 3806; E-mail: gita.ramjee@mrc.ac.za

Received December 20, 2011; Accepted January 24, 2012; Published January 28, 2012

Citation: Ramjee G, Daniels B (2012) Targeted Combination HIV Prevention Packages to Halt the Global HIV Epidemic. J AIDS Clinic Res S4:002. doi:10.4172/2155-6113. S4-002

Copyright: @ 2012 Ramjee G, et al. This is an open-access article distributed under the terms of the Creative Commons Attribution License, which permits unrestricted use, distribution, and reproduction in any medium, provided the original author and source are credited. 
high risk behaviors such MSM, sex workers, migrant workers and IDUs worldwide [5,7,13-16]. Concentrated epidemics in countries are defined as those with HIV prevalence of over $5 \%$ in at least one high risk population whose behavior makes them vulnerable to HIV, and the HIV prevalence in the general adult urban population of that country is less than $1 \%[15,17]$.

Given the worldwide call to reduce the global burden of HIV to zero new infections [3], it is imperative that each geographical region and individual countries within these regions take stock of their epidemic, identify whether their epidemic is generalized or concentrated and develop a package of appropriate interventions suited to their high risk population to curb HIV incidence rates. In this paper, we aim to identify regions with either concentrated or generalized epidemics and suggest appropriate HIV prevention packages consisting of both current and new proven biomedical options.

\section{HIV Prevention}

Treating HIV infected people with life saving anti-retroviral therapy (ART) has been hailed a success whereby HIV infection has now become a chronic, treatable infection improving the survival of those infected [10]. However, economic analysis suggests that HIV prevention is more cost-effective than treatment of HIV [18]. HIV prevention interventions range from the most basic of abstinence, HIV testing and counseling, behavioral change messages and condom usage to more sophisticated intervention including biomedical and structural interventions. Several HIV prevention options have been researched either through observational studies or randomized control trials (RCTs) as discussed below.

\section{Behavioral interventions}

HIV counseling and testing (HCT): Routine HIV testing and counseling is the cornerstone of HIV prevention. HIV counseling and testing provides individuals, couples, and families with the opportunity to learn their HIV status and receive personalized risk reduction counseling and further care appropriate to their status. HIV counseling and testing can also assist communities in addressing issues of denial, discrimination, stigma and prevention associated with HIV/ AIDS $[19,20]$. Studies have shown that testing HIV positive resulted in a significant reduction in high risk behavior, but not among people testing HIV negative [21]. A Meta analysis of studies conducted between 1988 and 2003 suggests that MSM showed a reduction in unprotected anal sex in 4 studies (59, 65, 25 and $59 \%$ ); two studies suggested a reduction in unprotected anal and vaginal sex in both men and women (63 and 59\% in men and 59 and 56\% in women); one study suggested a reduction in oral sex in both men and women after learning their status ( $41 \%$ in men and $34 \%$ in women); and a study in women showed reduction in unprotected vaginal or anal sex after learning their HIV status (52\%). This Meta analysis showed that on average, a $53 \%$ reduction in unprotected anal or vaginal sex is observed in men and women after learning their HIV status [22]. Being aware of their status made HIV-positive individuals half as likely to engage in risky sexual behavior compared to those who were unaware of their HIV status [21-24].

The use of mobile clinics to provide HIV rapid testing may be extremely useful for at-risk populations who normally do not seek care. One study evaluated the usability and post-test counseling rates of rapid HIV testing services for clients testing at a mobile clinic. The study showed that rapid HIV testing services may enhance the effectiveness of mobile STI/HIV clinics [25].
Delaying sexual debut: In women, a correlation has been shown between early age at sexual debut and subsequent risky sexual behaviors [26], such as decreased contraceptive and condom use, having multiple partners and higher incidence of sexually transmitted infections [27,28]. A study in Malawi showed an association between having sex at an early age and the incidence of HIV infection [29], while a household survey in South Africa revealed that $7.8 \%$ of women aged 15-24 had sexual intercourse by age 14, and risk of HIV infection was significantly increased if a woman had been sexually active for more than a year prior to the time of the survey [30]. Wand and Ramjee (2011) recently reported a correlation between the age of sexual debut and HIV incidence among women in the Methods for Improving Reproductive Health in Africa (MIRA) trial in Durban, South Africa $[31,32]$; most likely attributable to an increased number of sex partners in their lifetime. The delay of sexual debut may have been one of the crucial changes in behavior which led to a decline in HIV infection in Uganda [33,34].

Peer outreach and education: Peer education interventions pass on knowledge and encourage behavioral change in individuals that share the same demographic (e.g. age or gender) or risk behavior characteristics (e.g. sex workers, IDUs). This is based on the reasoning that peers have a strong influence on individual behavior, and that because the educators are part of the target group, they maintain a certain level of trust and comfort which allows for candid discussion around sensitive topics [35]. A systematic review and Meta analysis of 28 peer education interventions in developing countries showed a significant increase in HIV knowledge, increased condom use and reduced equipment sharing among IDUs. Although these programs demonstrated a moderate improvement of behavioral outcomes, there was no significant impact found on biological outcomes (such as STI infection) [35]. In Ahmedabad, India, a HIV prevention program including outreach, peer education, condom distribution and free STI clinics was implemented for commercial sex workers. During the 51 month period outreach workers and peer educators would distribute condoms, encourage commercial sex workers to visit the STI clinic and promote safer sex practices. They demonstrated that the intervention decreased HIV transmission by $54 \%$ and $51 \%$ among the sex workers and their clients [36]. Similarly, peer educators in Mombasa, Kenya, were able to increase protected sex among sex workers by providing condoms; STI and HIV education and facilitating HIV testing, treatment and care facilities [37]. Another study in Chiang Mai, Thailand evaluated the efficacy of a best practice, life-skills curriculum on methamphetamine use, sexual behaviors, and incident STIs with a peer educator intervention on methamphetamine and HIV risk behaviors among 18-25 year olds. The authors discovered that both interventions demonstrated reductions in methamphetamine use, decreased STIs and increased condom use [38].

The Stepping Stones study was a program using participatory learning approaches to build knowledge, communication skills and risk awareness and to encourage critical reflection to improve sexual health. Although the incidence of HIV was not lowered, the program showed a $33 \%$ reduction in Herpes simplex virus-2 (HSV-2) incidence and improved several reported risk behaviors in men, such as transactional sex and intimate partner violence [39].

Mass media: A systematic review of 24 mass media interventions aimed at changing HIV-related knowledge, behaviors and attitudes in developing countries. The most commonly reported outcomes were condom use (17 studies) and awareness of the modes of HIV transmission (15 studies), followed by reduction in risky sexual 
behavior (8 studies), perceived risk of becoming infected with HIV/ (6 studies), interpersonal discussion about condom use or HIV (6 studies), ability to negotiate condom use (4 studies) and abstinence from sex (3 studies). The review produced mixed results, and in those studies where there was statistical significance, the effect size was also small. However, at least $50 \%$ of the studies showed a positive impact on both the reduction of risky sexual behavior and the knowledge of HIV transmission [40]. Makgabaneng is a radio program based on the Modeling and Reinforcement to Combat HIV/AIDS (MARCH); the strategy implemented a radio serial drama together with community reinforcement strategies with the aim of promoting the use of PMTCT services and encourage safer sexual behavior. After controlling for pregnancy, demographic and other variables, the authors found that women who could name a PMTCT character in the drama as their favorite character without prompting were twice as likely to undergo HIV testing during pregnancy compared to those who did not [41]. The VISION project was designed to increase the use of family planning, HIV/AIDS services and child survival using a mass-media campaign focusing on HIV prevention and reproductive health in Nigeria. The campaign made use of radio, television and printed advertisements, and exposure was 59, 24 and $47 \%$ respectively. They found that people with high program exposure were one and a half times more likely to have discussed HIV with their partner and over twice as likely to know that the risk of HIV infection is reduced by condom use [42]. Several social marketing and health communication programs focusing on reproductive and HIV prevention programs have been implemented in Zambia to address reproductive health problems. Van Rossem and Meekers (2007) found that Zambians who had been exposed to these radio and television programs were more likely to have ever used a condom, while men highly exposed to a brand of condoms' marketing communication were more likely to have ever used a condom as well as having worn a condom during their last sex act [43].

Partner reduction: African men and women can often have more than one concurrent partnership that may overlap for months or years. A WHO study showed that $55 \%, 22 \%$ and $18 \%$ of men in Lesotho, Zambia and Tanzania respectively, reported having two or more regular, ongoing sexual partnerships in the previous year [44]. The role of these concurrent sexual partnerships is recognized as being increasingly significant for the transmission of STIs, particularly heterosexual HIV. Empirical and modeling evidence imply that concurrent partnerships can increase the size of an HIV epidemic, its persistence within a population and the speed at which it infects a population [45]. Data from nationally-representative surveys conducted in Rwanda, Zimbabwe, Cameroon and Uganda between 2004 to 2006 (which included HIV testing of men and women) was examined to assess the association between multiple sexual partnerships and faithfulness and the risk of HIV infection. The data showed that the risk of being HIVinfected increased with the number of lifetime sexual partners and decreased with the level of spousal faithfulness demonstrated [46]. The prevalence of HIV in Uganda declined considerably subsequent to an extensive "Zero Grazing” campaign in the 1980's. Surveys conducted in 1989 and 1995 by the World Health Organization found a greater than $50 \%$ reduction in the number of people reporting casual and multiple partners $[47,48]$. Partner reduction and fidelity appear to be the main behavioral changes responsible for the decline in Kenya's HIV infection rates. The HIV rate has also dropped in Zimbabwe, Côte d'Ivoire, Malawi and Ethiopia along with reports of similar behavior changes. In 2006, Swaziland conducted an aggressive campaign focusing on the dangers involved with having a 'secret lover', and the number of people reporting two or more partners in the last month halved.
However, there are few established, reproducible strategies to reduce multiple sexual partners on a large scale. Still, Uganda has shown that mass mobilization of the community can effectively encourage behavior change and that combating stigma and partner reduction can be achieved [47]. Thailand's " $100 \%$ condom" approach in brothels was followed by a twofold reduction in the number of men who reported participating in commercial and other casual sex. Gay men in the USA and Europe responded to the risk of AIDS by decreasing their number of partners. Cambodian surveys showed that the proportion of men reporting that they had paid sex reduced, as did their HIV infections. The number of HIV infections in the Dominican Republic have also declined with men having reported increased condom use with sex workers and partner reduction [48].

\section{Structural interventions}

Structural factors that influence the HIV epidemic have been defined as social, physical, organizational, cultural, legal, economic or policy aspects of the environment that impede or facilitate efforts to avoid HIV infection [49]. Structural factors that can affect HIV risk are gender inequality and sexual violence, poverty and labor migration which have been linked to an increased risk of HIV transmission $[6,49]$. Economic instability and societal transitions may increase sexual mixing due to survival sex work, migration and increased population densities in urban areas for example [21]. Structural factors can act as barriers to individually oriented HIV prevention and care services and the adoption of HIV-preventive behaviors, such as the fear of HIV/ AIDS-related stigma and discrimination which discourages people from seeking HIV counseling and testing and from disclosing their status to their sexual partner [49].

Policy structural factors: Structural approaches to reduce vulnerability and risk in sex workers have included policy actions such as the $100 \%$ condom use policy implemented by brothel and bar managers and the police in Thailand and the Dominican Republic $[21,49]$. It has been shown that policy-level support and empowerment strategies for sex workers can improve acceptability, adherence and coverage of HIV prevention programs by reducing stigma and discrimination [20]. The best example of successful policy changes by a country and how they decreased HIV transmission is Uganda. Uganda's government committed itself to extensive health education campaigns, training of trainers, mass media, countrywide messaging and district mobilization (making use of posters, flyers, videos, competitions, songs, books, public gatherings and documentaries). This resulted in changes in social norms, sexual behavior and HIV prevalence [50].

The Cuban state provides free food, shelter and treatment to people living with HIV and AIDS in sanatoria that keep them separated from the rest of the Cuban population. Although this has been successful in curbing their HIV epidemic, the ethical issues of enforced isolation need to be considered. Research in Uganda and Thailand has highlighted the link between government acknowledgement of the significance of HIV and the development of more successful government interventions to HIV [51].

Economic/Social structural factors: The connection between economic development and HIV vulnerability has long been established. An example is the Aksomo dam project in Ghana in the 60 's which contributed to the spread of HIV in the 80's and 90's. Men living in the nearby Krobo area, worked on the construction of the dam while Krobo women provided services to them, including paid sex. When the Krobo base was destroyed by the construction of Lake Volta, 
these women and their daughters went overseas to work as sex workers, which contributed to the spread of HIV in the area. Similarly, in Haiti a large community was displaced by the building of a large hydroelectric plant, and their migration produced changes in sexual union and sex work patterns, putting them at risk of HIV infection [51].

Microfinance programs seek to alleviate poverty by providing access to credit, savings or business skills. A study in South Africa showed that an integrated curriculum of gender equity, anti-violence work and HIV/AIDS education with an existing microfinance program showed a 55\% reduction in domestic violence and higher levels of HIV-related communication by women. Women were also more likely to have accessed HCT and less likely to have had unprotected sex at their last sexual intercourse [52]. Cash transfer programs are based on the theory that economic instability and poverty drive risk behavior in young women. A randomized trial in Malawi showed that girls receiving cash transfers had a lower prevalence of HIV and HSV-2 than those who were not (this was linked to school attendance). This is due to delayed sexual debut, less sexual activity, younger and fewer partners and reduced transactional sex [20]. Another trial in Tanzania suggested that both men and women receiving monetary incentives had a $25 \%$ lower incidence of infection of STIs than controls. In contrast, another Malawian study showed no effect in HIV incidence among men and women who were paid to remain HIV negative [20]. A project in Nairobi, Kenya, provided women engaged in sex work with relevant HIV and safe sex education as well as training them in small business management and providing startup funds for their businesses. Not only did they see an increase in condom use and a decline in the number of sexual partners these women had, but the women also experienced an increased sense of pride and wellbeing [51].

Migration and migrant labor has been long regarded as a contributory factor in increased risk of HIV transmission and acquisitions [53]. Migration has played a role in HIV prevalence among Dominican migrants to the USA, rural to urban migrants in Zaire and Haiti, female sex workers in Ghana, Thailand, Zimbabwe and the Philippines and male sex workers and other MSM in Brazil [51]. Political instability aggravates poverty and stimulates migration to urban areas, where many factors such as STI prevalence, sexual-union patterns, gender-bias and government inattention to AIDS facilitate HIV transmission [51].

In South Africa, Ramjee and Gouws (2002) reported an HIV prevalence of $56 \%$ among truck drivers visiting sex workers [54]. In Tanzania, a project was started to raise HIV awareness, distribute and promote condom use, reduce the overall number of sexual partners and encourage peer-based STI/HIV education among truck drivers. The project found that HIV awareness increased and the number of condoms distributed increased by 100 000. In Zimbabwe, interviews, focus groups, and participant observations were conducted with 74 truck drivers. These interviews demonstrated that truck drivers had a high prevalence of prior STIs and low levels of knowledge about using condoms as an HIV prevention tool. Prevention interventions aimed at increasing trucker wages, decreasing their overtime worked and providing a means by which their spouse and/or family can accompany them on long trips could reduce HIV transmission in these groups [51,54]. The Burmese government addressed the vulnerability of truck drivers by improving the road surfaces, which led to reduced transportation times and therefore reduced the number of overnight stops made by the drivers along their route. Australia implemented a broad-based structural response which successfully managed the HIV epidemic among MSM and IDUs. These included encouragement and funding for the active involvement of affected communities, supportive national and state-level policy and establishment of specific research centers to inform the response. This has resulted in a willingness to communicate openly about risk and to reduce harm as well as contributing to the partnership between policy makers, researchers and community groups and has contained the epidemic among target groups [49].

Cultural factors: Stigma and fear of disclosure has been a large factor in individuals seeking HIV testing and subsequent treatment and care. Stigma, discrimination, blame, and denial are potentially the most complicated aspects of HIV/AIDS to address, however addressing them is essential to preventing HIV transmission and lessening the effects of the disease on individuals, families, and communities. Stigma can occur at different levels, including interpersonal, community, institutional (e.g. workplaces, schools and health facilities) and legislative levels. General interventions addressing stigma have focused mostly on creating changes in individual attitudes, knowledge, and behaviors rather than broader social and environmental change [55]. Stigma and discrimination also affect the MSM population a great deal. Same sex relationships are criminalized in 37 of 54 African countries, and are punishable by death in four of these countries [56].

The Vietnam government realized that stigma was undermining the countries' investment in HIV services. They therefore implemented various community activities, such as implementation of the action plans with technical support, stigma-reduction sensitization workshops for authorities and representatives of social organizations, a workshop for community members to develop their own stigmareduction action plans and monitoring and evaluation of the program activities. Not only did they see an increase in HIV awareness, but they found a decrease in value-driven stigma, a decrease in discrimination and a decrease in fear-driven stigma [57].

Gender inequality: Many structural interventions aim to change the social norms that worsen HIV vulnerability. Program H in Brazil encouraged young men to question their traditional gender norms and encouraged discussion and reflection on the detriment of inequitable definitions of masculinity and the advantages of more gender unbiased behavior. The South African IMAGE project aimed to decrease genderbased HIV vulnerabilities like women's economic dependency on men, sexual violence and women's lack of knowledge about HIV and its transmission. This was done by partnering with a local microfinance institution to allow women to engage in microenterprises, while offering them HIV education and a platform to discuss action against gender-based violence. Not only did the women improve their household wellbeing and empowerment, but a significant reduction in gender-based violence was observed [49].

\section{Biomedical HIV prevention}

Male circumcision: Male medical circumcision (MMC) as an HIV prevention option as been hailed as one of the success stories in biomedical HIV prevention [58]. In the late 1980s, a prospective study found that HIV was eight times higher among uncircumcised men than their circumcised counterparts. Numerous cross-sectional, casecontrol and prospective studies were conducted with men in various parts of Africa that have provided further support for this association [59]. Three randomized controlled trials revealed that circumcision provided substantial protective effects from HIV [60-62]. In a South African trial, male circumcision provided a $60 \%$ protection from HIV infection [60], while it reduced the risk of HIV infection by $50 \%$ in Uganda [62]. The intervention is currently being rolled out in many 
countries in sub-Saharan Africa [63]. Despite a meta-analysis of 17 studies showing that the association between circumcision and HIV infection among MSM is protective (but not statistically significant) [64], scientists doubt the efficacy of circumcision preventing HIV transmission in MSM [65]. The major factor determining the success of male circumcision in the prevention of HIV transmission is the uptake and acceptability of male circumcision within traditionally noncircumcising communities in these countries, in addition to availability of adequate human resources in countries with generalized epidemics such as Southern and Eastern Africa [66].

Messages should highlight the introduction of safe and affordable circumcision services as well as mobilize communities in a culturally sensitive manner highlighting the benefits of the circumcision services [67]. Studies conducted by Herman-Roloff et al. (2011) reported that circumcision for adult men was viewed as a barrier to MC implementation since it was a conception that MC was associated with adverse effects (AEs). As part of an implementation strategy for $\mathrm{MC}$, governments are now considering the ideal age for $\mathrm{MC}$; regarding the concept of MC associated AEs, development as well as the improvement of communication campaigns campaigns should be considered. Such campaigns will aid in dismissing misconceptions, that medical MC results in severe, untreatable AEs [68]. In some countries such as Uganda, the decision to undertake medical MC is not solely an individual decision, female partners are also involved in the decision making process. Therefore, Informational campaigns should target both men and women on issues surrounding medical MC [69]. Additionally, the recruitment drive in medical MC embarks on featuring prominent people such as media personalities, governmental officials, etc, and then the public will most likely be willing to participate in the programme [70].

Condoms: Male condoms have been found to be highly effective in reducing HIV incidence. When used correctly and consistently, they have been shown to be $95 \%$ effective at preventing HIV, but have proven only $70 \%$ effective when not used consistently or correctly. However, the use of male condoms might be unsuccessful in countries where gender and social inequalities are widespread and in poor economies. Although the female condom has demonstrated the prevention of STIs they have not been evaluated for HIV prevention and tend to be expensive, unavailable and unfamiliar to women [21]. Golombok and colleagues (2001) found that the use of water-based lubricants with condoms reduced the percentage of condom breakage compared to oil-based lubricants or no lubricants in men that have sex with men [71], thereby increasing the efficacy of condoms in preventing HIV transmission in MSM. Several lubricants have been tested in vitro for activity against HIV and shown to block HIV infection of lymphoma cells, although this may not translate to protection from HIV during vaginal or anal sex [72].

Treatment of sexually transmitted infections: Many pathways by which STIs might increase the susceptibility and infectiousness of individuals carrying HIV have been identified. The first scientific test to prove that treatment of STIs could reduce the spread of HIV at a community level was in the Mwanza district in Tanzania in the early 1990s [6]. This cluster-randomized trial with intensive syndromic management of bacterial STIs resulted in a $40 \%$ reduction in HIV incidence in treatment versus control populations [73]. Despite biological evidence for STI treatment as a possible HIV prevention option, efficacy has not been proven in several randomized controlled trials [74,75]. Several meta-analysis and observational studies have demonstrated that HSV-2 infection might increase the risk of HIV infection [76,77]. Despite this, three large-scale trials demonstrated no proof of an effect of HSV-2 suppressive therapy on HIV acquisition [78-80]. Nonetheless, STI treatment remains a critical public health intervention.

Mother to child transmission of HIV (MTCT): The World Health Organisation has a four pronged approach to preventing mother to child transmission (PMTCT) of HIV: 1) HIV prevention in women of childbearing age; 2) prevention of unintended pregnancies in women that are HIV positive; 3) prevention of HIV transmission from women with HIV to their infants using ART; and 4) provision of treatment, care and support to women that are HIV positive and their families [20]. Prevention of mother to child transmission has been a successful intervention in developed countries, where mother to child transmission of HIV is almost eradicated [21]. PMTCT programs in most resource-limited countries are delivered in the context of maternal, newborn and child health services. These services are often a woman of childbearing age's only access to HIV prevention, treatment, care and support services. As part of the four pronged approach, prevention of HIV can include a wide variety of interventions delivered to women of childbearing age both at the health facility and in the community. These can include HIV testing and counseling, education on HIV and STIs, promotion of condom-based protection and harm reduction interventions for injection drug users. Second, these health care facilities are also able to encourage contraceptive use to prevent HIV positive women from becoming pregnant. Third, PMTCT programs can assist in preventing transmission of HIV to her infant by providing HIV testing and counseling for pregnant women and their partners, clinical assessment to determine the eligibility of mothers for treatment (CD4 count), antiretroviral therapy for qualifying mothers for their individual health or antiretroviral prophylaxis for their infants to inhibit vertical transmission of HIV, safer delivery practices and counseling about feeding infants and children when a family member has HIV [81]. The MTCT-Plus Initiative was developed by the WHO with the aim to provide families in resource-limited settings with lifelong treatment and care for HIV/AIDS. This program seeks to decrease the MTCT of HIV, strengthen local health care, promote VCT and empower people living with HIV/AIDS. The program hopes to provide integrated services such as family planning, counseling and to support, clinical care and prevention and, when indicated, antiretroviral therapy. This program utilizes the WHO guidelines for ARV eligibility (i.e. CD4 cells $<350$ cells per $\mathrm{mm} 3$ and WHO stage II or III HIV disease or asymoptomatic adults with $\leq 200 \mathrm{CD} 4$ cells per $\mathrm{mm} 3$ and all adults with WHO stage IV HIV disease) [82]. The WHO recommend a triple-drug antiretroviral treatment for women who are eligible for ART and a combination prophylaxis antiretroviral regimen for women who are not eligible for ART (preferably zidovudine from 28 weeks of gestation; zidovudine, lamivudine, and a single dose of nevirapine during delivery; and zidovudine and lamivudine for 7 days after delivery to reduce the development of nevirapine resistance). A single dose of nevirapine and 1-4 weeks of zidovudine are recommended for newborn infants. However, the use of single-dose nevirapine alone is still recommended where more effective regimes are impossible or inaccessible [83].

Clean needle exchange programs: Various core interventions can be effective in preventing HIV in IDUs, including the provision of clean syringes and needles (usually through needle and syringe programmes; NSPs) to avoid HIV transmission; opioid substitution therapy (OST) for treatment of opioid dependence, particularly methadone and buprenorphine, which leads to reductions in drug injection and HIV risk behaviours; and other forms of drug treatment 
might also reduce injecting risk [84]. Injection drug users also face the risk of sexual transmission of HIV and drug treatment and condom provision have shown to reduce their sexual risk behavior [84]. Several distribution models have been developed, including: vending machines selling injecting equipment; free needle syringe programs, through fixed and outreach models; distribution of equipment by IDUs or their peers and sales of injecting equipment, typically through pharmacies [85]. Several studies have presented a convincing argument that needle syringe programs can be cost-effective in reducing the spread of HIV among IDUs considerably without impacting on increasing injecting drug use at the individual or the societal level $[86,87]$.

Test to treat: This prevention mechanism makes use of ART to decrease the forward transmission of HIV, since treatment reduces the HIV viral load and therefore infectiousness. The HPTN052 trial examined the ability of ART to stop HIV transmission from an index partner to his or her sexual partner. The study enrolled 1763 couples in nine countries, where one partner was HIV positive and the other was HIV negative. It demonstrated a $96 \%$ reduction in the number of HIV transmissions from the HIV positive partner due to early initiation of ART, when compared to delayed therapy (as per local standard of care). It is believed that the sustained suppression of HIV1 in the genital secretions resulting from ART is the most probable mechanism for the prevention of HIV in this study $[20,88]$. There are several considerations when employing a test and treat method to HIV prevention, such as: implementation of universal testing, the stage of infection of the HIV-positive individual, behavioral disinhibition, the benefit to the infected individual, and cost- effectiveness [89].

Pre-exposure prophlylaxis: Highly active antiretroviral therapy (HAART) usually contains three or more ART medications to treat HIV and it has radically changed HIV-associated morbidity and mortality and has improved the quality of life of HIV-infected individuals. The focus therefore has been on whether antiretroviral drugs could be used to reduce the epidemic as pre-exposure prophylaxis (PrEP) to prevent HIV [90,91]. ART has already considerably decreased mother to child HIV transmission and could possibly be used to prevent the sexual transmission of HIV by reducing the HIV concentration systemically or in the genital tract of HIV-positive individuals [90]. ART drugs currently tested as PrEP are Tenofovir (TDF) and Truvada (TDF/FTC). A phase II, randomized, double-blinded, placebo-controlled trial, completed three years ago in Cameroon, Nigeria, and Ghana (the West Africa TDF trial in 2004), established the safety of daily oral tenofovir for HIV prevention among high-risk women who also received HIV testing, counseling, and condoms [92].

This data encouraged public health researchers to conduct efficacy trials for PreP in high-risk populations around the world. The targeted populations in these studies are heterosexual men and women, MSM, discordant couples and IDUs (Table 1). TDF containing products were used in these trials, comprising TDF alone or in combination with FTC, and all are assessing daily use with the exception of one

\begin{tabular}{|c|c|c|c|c|c|c|}
\hline & Study population & Location & $\begin{array}{l}\text { Route of HIV } \\
\text { transmission }\end{array}$ & Intervention & Outcome & Comments \\
\hline CAPRISA $004^{2}$ & $\begin{array}{l}889 \text { heterosexual women at high } \\
\text { risk of infection, aged 18-40years }\end{array}$ & South Africa & Vaginal & $\begin{array}{l}\text { Coitally-dependent } \\
\text { TFV } 1 \% \text { gel (two dos- } \\
\text { es up to } 12 \mathrm{~h} \text { precoitus } \\
\text { and postcoitus) }\end{array}$ & $\begin{array}{l}39 \% \text { protection; } 54 \% \\
\text { protection calculated } \\
\text { in participants using } \\
>80 \% \text { of doses }\end{array}$ & $\begin{array}{l}\text { High TFV-DP concentration } \\
\text { in vaginal and cervical tissue } \\
\text { critical for efficacy }\end{array}$ \\
\hline $\mathrm{iPrEX}^{4}$ & $\begin{array}{l}2499 \text { MSM at high risk of infection; } \\
\text { approximately } 70 \% \text { of mixed eth- } \\
\text { nicity; mean age in TDF/FTC group } \\
27-5 \text { years }\end{array}$ & $\begin{array}{l}\text { North and South } \\
\text { America, Thailand, } \\
\text { South Africa }\end{array}$ & Rectal/penile & Daily oral TDF/FTC & $\begin{array}{l}44 \% \text { protection; } 92 \% \\
\text { protection calcu- } \\
\text { lated for subjects } \\
\text { with detectable drug } \\
\text { concentrations }\end{array}$ & $\begin{array}{l}\text { High TFV-DP concentrations } \\
\text { in rectal tissue might be criti- } \\
\text { cal for efficay }\end{array}$ \\
\hline TDF $^{5}$ & $\begin{array}{l}1200 \text { sexually active adults; } 55 \% \\
\text { male, } 45 \% \text { female; } 94 \% \text { unmarried; } \\
\text { approximately } 90 \% \text { age } 21-29 \text { years }\end{array}$ & Botswana & Vaginal/penile & Daily oral TDF/FTC & $63 \%$ protection & $\begin{array}{l}>30 \% \text { did not complete } \\
\text { study; cannot draw definitive } \\
\text { conclusions for women and } \\
\text { men separately }\end{array}$ \\
\hline $\mathrm{PIP}^{6}$ & $\begin{array}{l}4747 \text { heterosexual serodiscordant } \\
\text { couples; } 38 \% \text { negative-female, } \\
68 \% \text { negative-male partner, } 98 \% \\
\text { married; median age } 33 y e a r s\end{array}$ & $\begin{array}{l}\text { Botswana, Kenya, } \\
\text { Rwanda, South Africa, } \\
\text { Tanzania, Uganda, } \\
\text { zambia }\end{array}$ & Vaginal & $\begin{array}{l}\text { Daily oral TDF or TDF/ } \\
\text { FTC }\end{array}$ & $\begin{array}{l}62 \% \text { protection with } \\
\text { TDF alone; } 73 \% \text { pro- } \\
\text { tection with TDF/FTC }\end{array}$ & $\begin{array}{l}\text { Discordant couples may be a } \\
\text { distinct, unique population }\end{array}$ \\
\hline FEM-PrEP ${ }^{7}$ & $\begin{array}{l}1951 \text { heterosexual women at high } \\
\text { risk of infection aged 18-35 years }\end{array}$ & $\begin{array}{l}\text { Kenya, South Africa, } \\
\text { Tanzania }\end{array}$ & Vaginal & Daily oral TDF/FTC & $\begin{array}{l}\text { Trial discontinued for } \\
\text { futility in April, } 2011\end{array}$ & $\begin{array}{l}\text { Adherence assessment with } \\
\text { monthly clinical samples to } \\
\text { measure drug concentration } \\
\text { is pending }\end{array}$ \\
\hline $\begin{array}{l}\text { VOICE } \\
(\mathrm{MTN}-003)^{3}\end{array}$ & $\begin{array}{l}5029 \text { heterosexual } \\
\text { women aged } \\
18-45 \text { years }\end{array}$ & $\begin{array}{l}\text { Uganda, South Africa, } \\
\text { Zimbabwe }\end{array}$ & Vaginal & $\begin{array}{l}\text { Daily oral TDF or daily } \\
\text { oral TDF/FTC or daily } \\
\text { topical TFV gel }\end{array}$ & $\begin{array}{l}\text { Oral TDF group discon- } \\
\text { tinued for futility in } \\
\text { September, } 2011 ; \text { TFV } \\
1 \% \text { gel and placebo gel } \\
\text { groups discontinued } \\
\text { for futility in November, } \\
2011 ; \text { oral TDF/FTC } \\
\text { group continues }\end{array}$ & $\begin{array}{l}\text { For TDF, the tissue con- } \\
\text { centration may be critical; } \\
\text { for TFV } 1 \% \text { gel, adherence } \\
\text { analysis is pending }\end{array}$ \\
\hline HPTN $052^{1}$ & $\begin{array}{l}1763 \text { heterosexual serodiscordant } \\
\text { couples; } 50 \% \text { negative- females, } \\
50 \% \text { negative-male partner; } 94 \% \\
\text { married; } 61 \% \text { aged } 26-40 \text { years }\end{array}$ & $\begin{array}{l}\text { Bostwana, Kenya, } \\
\text { Malawi, South Africa, } \\
\text { Zimbabwe, Brazil, } \\
\text { India, Thailand }\end{array}$ & Vaginal/Penile & $\begin{array}{l}\text { Immediate or delayed } \\
\text { ART in HIV-infected } \\
\text { partner }\end{array}$ & $96 \%$ protection & $\begin{array}{l}\text { Suppression of viraemia on } \\
\text { therapy assured by routine } \\
\text { monitoring }\end{array}$ \\
\hline
\end{tabular}

Source: Angela D M Kashuba, Kristine B Patterson, Julie B Dumond,Myron S Cohen (2011) Pre-exposure prophylaxis for HIV prevention: how to predict success The Lancet DOI:10.1016/S0140-6736(11)61852-7.

Table 1: Antiretroviral-based HIV Prevention Studies. 
Citation: Ramjee G, Daniels B (2012) Targeted Combination HIV Prevention Packages to Halt the Global HIV Epidemic. J AIDS Clinic Res S4:002. doi:10.4172/2155-6113.S4-002

Page 7 of 14

pilot study of intermittent dosing [91]. A recent study (iPrEx) among MSM showed that a fixed dose of a combination of TDF and FTC could provide protection of up to $44 \%$ [93]. Another group (Partners in PreP (PIP) [94]) announced the outcome of their interim analysis which suggested that treatment with either Truvada or Tenofovir of the HIV-negative partner in HIV serodiscordent couples reduced HIV acquisition from HIV-positive partner by almost $62 \%$ in those taking Tenofovir and $73 \%$ in those taking Truvada. Based on these results, the study was unblinded to allow all discordant participants in this RCT to receive the intervention [95]. A smaller study conducted by the Centre for Disease Control showed that Truvada decreased HIV incidence in heterosexual men and women [96] (Table 1).

Unfortunately, two studies among women randomized to receive oral PreP (Truvada in FEM-PrEP and Tenofovir in Vaginal and Oral Interventions to Curb the Epidemic (VOICE)) failed to show an effect of oral PrEP on HIV prevention among women in Africa. FEM-Prep was a phase III, randomized, placebo-controlled clinical trial designed to assess the safety and effectiveness of a daily dose of Truvada for HIV prevention in sub-Saharan African women. In April 2011 an interim review by the Data Safety and Monitoring Board (DSMB) decided that the study would be unlikely to show effectiveness in preventing HIV if continued [97]. In September 2011, the VOICE DSMB met and it was decided that the VOICE trial would be unlikely to show effectiveness in HIV prevention by the oral Tenofovir arm of the study and recommended that this arm of the study be dropped [98] (Table 1).

Microbicides for HIV prevention among women: Numerous products have been developed for use as microbicides to prevent transmission of HIV in women. Several potential microbicides with varying action have been tested for HIV prevention. These include surfactants [99-101] acid buffers [102], and polyanions [103106]. Unfortunately none were successful. The next generations of microbicides include the use of antiretrovirals (ARVs) in the microbicide gel formulation. It was hoped that ARV-containing microbicides, such as Tenofovir gel, would show more promise in preventing HIV transmission. The CAP004 study showed that Tenofovir $1 \%$ gel was able to reduce the risk of HIV acquisition by $39 \%$ (95\% CI 6-60) [107]. Unfortunately, these results were not replicated in the large VOICE trial. The VOICE DSMB review in November 2011 found that $1 \%$ Tenofovir gel was unlikely to show any effect in preventing HIV when compared with a placebo gel [108] (Table 1). Another ongoing trial called FACTS (Follow-on African Consortium of Tenofovir Studies) will hopefully shed some light on the true effect of Tenofovir gel in preventing male to female transmission of HIV [96].

Vaccines: Five candidate vaccines have reached the phase IIB or III clinical trial testing stage: two used recombinant gp120 vaccines, the Step and Phambili trials used the MRKAd5 HIV-1 gag/pol/nef vaccine, and a combination prime (ALVAC-HIV) + boost (AIDSVAX B/E) strategy was used $[109,110]$. The recombinant gp 120 vaccine was tested in a phase $1 / 2$ trial of a monovalent subtype B gp120 vaccine among IDUs in Bangkok between 1995 and 1996 and followed by a similar trial of a bivalent subtype B/E rgp120 vaccine in 1998 . These trials established that rgp120 was immunogenic and safe. Based on these

\begin{tabular}{|c|c|c|c|c|c|}
\hline & Region & HIV Prevalence (\%) & Population & Intervention & References \\
\hline \multirow[t]{8}{*}{$\begin{array}{l}\text { Concentrated Epidemic } \\
(\leq 1 \%)\end{array}$} & Caribbean & 1 & Sex workers & $\begin{array}{l}\text { SPP, PMTCT,PrEP, Test } \\
\text { and Treat }\end{array}$ & $\begin{array}{l}3,5,21,58,59,60,62,63 \\
74,75,78-80,90,91\end{array}$ \\
\hline & Central and South America & 0.5 & MSM, IDU & SPP, NSP, Test and Treat & $\begin{array}{l}3,22,58,59,60,62,63 \\
74,75,78-80\end{array}$ \\
\hline & Oceania & 0.3 & MSM & $\begin{array}{l}\text { SPP, NSP, PrEP, Test and } \\
\text { treat }\end{array}$ & $\begin{array}{l}3,5,21,58,59,60,62,63 \\
74,75,78-80,90,91,115\end{array}$ \\
\hline & $\begin{array}{l}\text { North Africa and the Middle } \\
\text { East }\end{array}$ & 0.2 & IDU & $\begin{array}{l}\text { SPP, NSP, PrEP, Test and } \\
\text { treat }\end{array}$ & $\begin{array}{l}4,5,21,58,59,60,62,63 \\
74,75,78-80,90,91,115\end{array}$ \\
\hline & $\begin{array}{l}\text { Eastern Europe and Cen- } \\
\text { tral Asia }\end{array}$ & 0.8 & IDUs, sex workers, MSM & $\begin{array}{l}\text { SPP, NSP, PrEP, Test and } \\
\text { treat }\end{array}$ & $\begin{array}{l}3,5,21,58,59,60,62 \\
63,74,75,78-80,90,91 \\
115,116\end{array}$ \\
\hline & $\begin{array}{l}\text { Western and Central } \\
\text { Europe }\end{array}$ & 0.2 & IDUs & $\begin{array}{l}\text { SPP, NSP, PrEP, Test and } \\
\text { treat }\end{array}$ & $\begin{array}{l}5,21,58,59,60,62,63 \\
74,75,78-80,90,91 \\
115,116\end{array}$ \\
\hline & North America & 0.5 & MSM & $\begin{array}{l}\text { SPP, NSP, PrEP, Test and } \\
\text { treat }\end{array}$ & $\begin{array}{l}3,21,58,59,60,62,63 \\
74,75,78-80,90,91 \\
115,116\end{array}$ \\
\hline & South and South East Asia & 0.3 & IDUs, sex workers, MSM & $\begin{array}{l}\text { SPP, NSP, PrEP, Test and } \\
\text { treat }\end{array}$ & $\begin{array}{l}4,5,21,58,59,60,62 \\
63,74,75,78-80,90,91 \\
115,116\end{array}$ \\
\hline \multirow[t]{4}{*}{$\begin{array}{l}\text { Generalized Epidemic } \\
(>1 \%)\end{array}$} & Western Africa & 2 & Sex workers, MSM & SPP, PrEP, Test and treat & $\begin{array}{l}2,3,21,58,59,60,62,63 \\
74,75,78-80,90,91\end{array}$ \\
\hline & Central Africa & 6.3 & Sex workers & SPP, PrEP, Test and treat & $\begin{array}{l}2,3,21,58,59,60,62,63 \\
74,75,78-80,90,91\end{array}$ \\
\hline & Eastern Africa & $>5$ & IDUs, sex workers, MSM & $\begin{array}{l}\text { SPP, NSP PrEP, Test and } \\
\text { treat }\end{array}$ & $\begin{array}{l}2,3,21,58,59,60,62,63 \\
74,75,53-55,90,91\end{array}$ \\
\hline & Southern Africa & $>15$ & Sex workers & $\begin{array}{l}\text { SPP, PMTCT, PrEP, Test } \\
\text { and treat }\end{array}$ & $\begin{array}{l}1,2,5,21,58,59,60,62 \\
63,74,75,78-80,90,91\end{array}$ \\
\hline
\end{tabular}

Key:

SPP- Standard Prevention Package (HIV counseling and Testing, Condoms, STI treatment, Safe sex counseling, \pm Medical Male Circumcision)

MMC - Medical Male Circumcision

NSP- Needle \& Syringe Programs \& adherence counseling

Oral PrEP- Tenofovir and Truvada \& adherence counseling

Test and treat- ARV for HIV positives \& adherence counseling

Table 2: Global AIDS statistics (UNAIDS Report, 2010). 
Citation: Ramjee G, Daniels B (2012) Targeted Combination HIV Prevention Packages to Halt the Global HIV Epidemic. J AIDS Clinic Res S4:002. doi:10.4172/2155-6113.S4-002

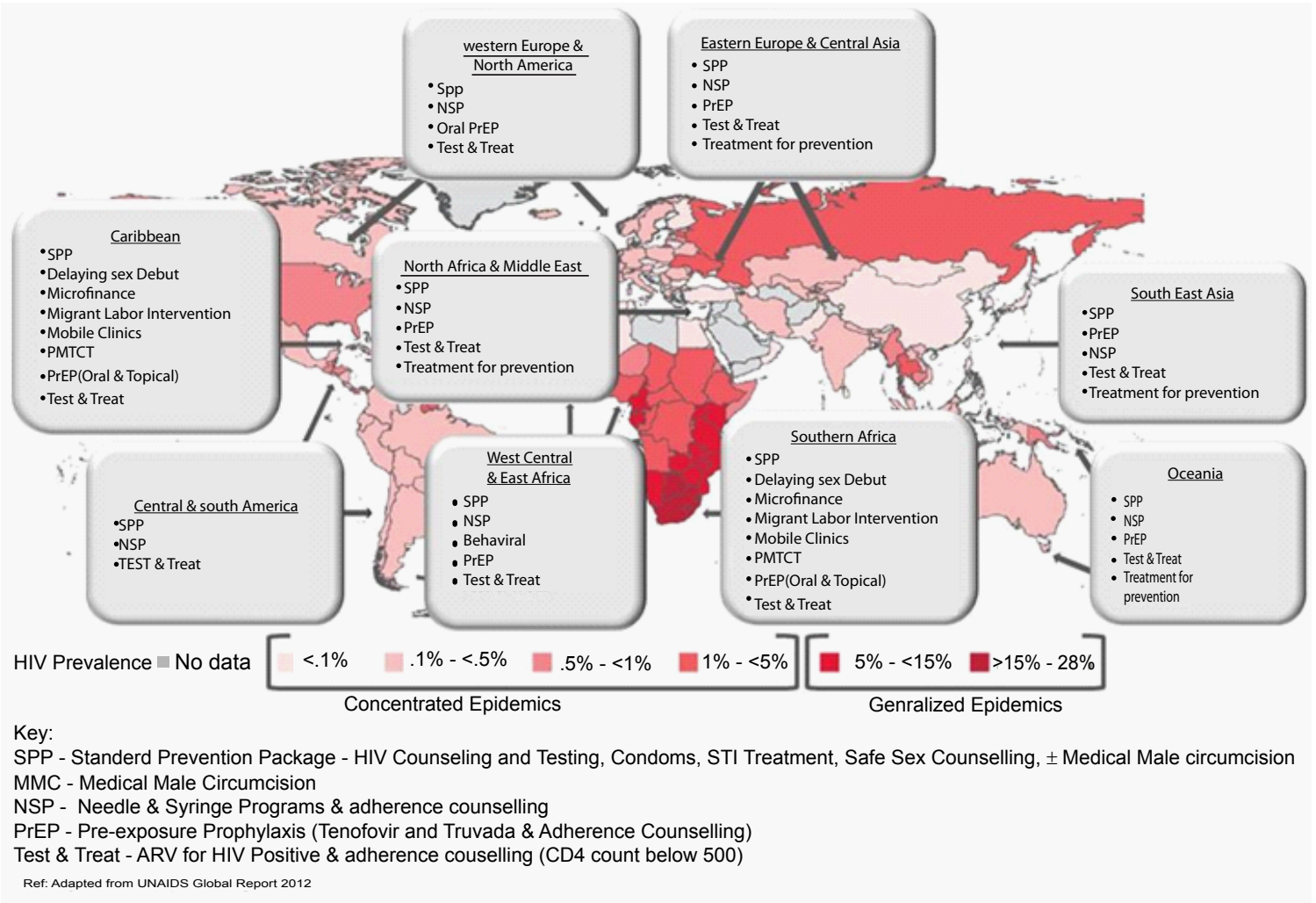

Figure 1: Regional HIV Epidemics and Corresponding Potential HIV Prevention Packages.

\begin{tabular}{|c|c|c|c|c|c|c|c|c|}
\hline Regions: & $\begin{array}{l}\text { Southern Africa } \\
\text { SA, Lesotho, }\end{array}$ & $\begin{array}{l}\text { West, Central \& } \\
\text { East Africa }\end{array}$ & $\begin{array}{l}\text { North Africa \& } \\
\text { Middle East }\end{array}$ & South East Asia & $\begin{array}{l}\text { Eastern Europe \& } \\
\text { Central Asia }\end{array}$ & Caribbean & $\begin{array}{l}\text { Central \& South } \\
\text { America }\end{array}$ & $\begin{array}{l}\text { Western Europe } \\
\& \text { North America }\end{array}$ \\
\hline Risk Group: & $\begin{array}{c}\text { All } \\
\text { (men, women, } \\
\text { adolescents) }\end{array}$ & $\begin{array}{l}\text { Sex Workers, } \\
\text { MSM, IDUs }\end{array}$ & IDUs & $\begin{array}{l}\text { Sex Workers, } \\
\text { MSM, IDUs }\end{array}$ & $\begin{array}{l}\text { Sex Workers, } \\
\text { MSM, IDUs }\end{array}$ & Sex Workers & MSM, IDUs & MSM \\
\hline \multicolumn{9}{|l|}{$\begin{array}{l}\text { HIV Prevention Inter- } \\
\text { ventions: }\end{array}$} \\
\hline SPP & $\checkmark$ & $\checkmark$ & $\checkmark$ & $\checkmark$ & $\checkmark$ & $\checkmark$ & $\checkmark$ & $\checkmark$ \\
\hline $\begin{array}{l}\text { Structural Interven- } \\
\text { tion }\end{array}$ & Multiple & Targeted & Targeted & Targeted & Targeted & Targeted & Targeted & Targeted \\
\hline \multicolumn{9}{|l|}{ Biomedical: } \\
\hline $\begin{array}{l}\text { ARV Prevention } \\
\text { \& Adherence Coun- } \\
\text { seling }\end{array}$ & $\begin{array}{l}\text { Discordant } \\
\text { Couples }\end{array}$ & $\begin{array}{l}\text { Discordant } \\
\text { Couples }\end{array}$ & - & $\begin{array}{l}\text { Discordant } \\
\text { Couples } \\
\text { MSM }\end{array}$ & $\begin{array}{l}\text { Discordant } \\
\text { Couples } \\
\text { MSM }\end{array}$ & $\checkmark$ & MSM & $\begin{array}{c}\text { Discordant } \\
\text { Couples } \\
\text { MSM }\end{array}$ \\
\hline $\begin{array}{l}\text { Treatment as Preven- } \\
\text { tion \& Adherence } \\
\text { Counseling }\end{array}$ & $\begin{array}{l}\text { Discordant } \\
\text { Couples }\end{array}$ & $\begin{array}{l}\text { Discordant } \\
\text { Couples }\end{array}$ & $\checkmark$ & $\checkmark$ & $\checkmark$ & $\checkmark$ & $\checkmark$ & $\checkmark$ \\
\hline $\begin{array}{l}\text { NSP \& Adherence } \\
\text { Counseling }\end{array}$ & IDUs & $\checkmark$ & $\checkmark$ & $\checkmark$ & $\checkmark$ & - & $\checkmark$ & - \\
\hline РMTCT & $\checkmark$ & $\begin{array}{c}\text { Women } \\
\text { Sex Workers }\end{array}$ & - & $\begin{array}{c}\text { Women } \\
\text { Sex Workers }\end{array}$ & $\begin{array}{c}\text { Women } \\
\text { Sex Workers }\end{array}$ & $\checkmark$ & - & \\
\hline
\end{tabular}

Table 3: HIV Epidemiology, Risk Groups and Potential Prevention Packages.

data, a phase 3 HIV-1 vaccine efficacy trial of AIDSVAX B/E (VaxGen) was conducted [111]. The Step Study was a randomised, placebocontrolled, phase II study evaluating the efficacy of the MRKAd5 HIV-1 gag/pol/nef vaccine in HIV-1 negative individuals who were at high risk of HIV-1 acquisition in North America, South America, the Caribbean and Australia. Adenovirus type 5 (Ad5) vector-based vaccines are one of the most immunogenic of cell-mediated immunity vaccines therefore this vaccine consisted of a mixture of rAd5 vectors expressing the HIV-1 gag, pol, and nef genes [112]. The Phambili trial tested the same vaccine as the Step study, but in South Africa [109]. The rgp120, Step and Phambili trials indicated neither benefit nor harm of the interventions in terms of HIV prevention [109,111-113]. 
After years of research, scientists saw a glimmer of hope in the vaccine trial conducted among 16,402 Thai men and women. The results of a double-blind, placebo-controlled efficacy trial evaluating four priming injections of a recombinant canarypox vector vaccine (ALVAC-HIV [vCP1521]) plus two booster injections of a recombinant glycoprotein 120 subunit vaccine (AIDSVAX B/E) in Thai men and women was announced in 2009. The study showed a vaccine efficacy of $31.2 \%$ and it was believed that the vaccine regimen offered further insight into future vaccine research [110]. There are currently 17 phase I, 4 phase I/II and 3 phase II clinical vaccine trials underway worldwide [114].

\section{Factors Driving the Regional HIV Epidemics}

\section{Regions with concentrated epidemics}

The Caribbean has the highest HIV prevalence of all regions outside of sub-Saharan Africa, at approximately 0.9\% [4]. However, the total number of people living with HIV in the Caribbean is small and has not varied greatly since the late 1990s. The main mode of HIV transmission in this region is unprotected heterosexual sex (paid sex in particular) $[3,5]$, while IDUs contributes to the spread of HIV in Bermuda and Puerto Rico [3] (Table 2).

The Central and South American HIV epidemics have changed little in recent years, with about one third of HIV infected people living in populous Brazil. The prevalence of adult HIV in Brazil has remained under $1 \%$ for the past decade. HIV is transmitted mostly by networks of MSM in this region, although social stigma has kept many of these epidemics hidden. Another main route of HIV transmission in this region is IDU. The older epidemics in South America are showing that heterosexual HIV transmission is increasing [3].

Western, Central Europe and North America have shown evidence of resurgent HIV epidemics among MSM (especially Germany, Canada, Spain, the Netherlands and the USA) [3]. MSM is the most important mode of transmission in this region, followed by heterosexual transmission, with IDU transmission having declined, although it remains the main mode of transmission in Estonia, Latvia, Lithuania and Poland [5].

Reliable data on the HIV epidemics in North Africa and the Middle East are scarce and therefore difficult to track. The available evidence points to increases in HIV prevalence, new HIV infections, and AIDS-related deaths. With the exceptions of Djibouti and southern Sudan, the HIV prevalence is low. Injection drug use is thought to be highest in the Islamic Republic of Iran. Contaminated drug-injecting equipment play a role in the epidemics of Algeria, Egypt, the Libyan Arab Jamahiriya, Oman, Morocco, the Syrian Arab Republic, Lebanon, and Tunisia $[4,5]$.

The number of people in Eastern Europe and Central Asia living with HIV has almost tripled since 2000 and reached an estimated total of 1.4 million in 2009. The Eastern Europe and Central Asia HIV epidemics are driven mainly by IDUs, sex workers and, to a lesser extent, MSM and partners of IDUs [3-5,115,116].

In South East Asia, the number of people living with HIV has been stable for the last five years. The only country with prevalence close to $1 \%$ is Thailand although its epidemic appears to be stable. The HIV incidence in Nepal, India and Thailand, decreased by more than $25 \%$ between 2001 and 2009, remained stable in Malaysia and Sri Lanka and increased by $25 \%$ in Bangladesh and the Philippines [3,5]. In most of these regions, the epidemics appear stable, despite the overall trends hiding important variation in the epidemics, both within and between countries when national epidemics are concentrated in a relatively small number of provinces. For example, in China, five provinces report just over half (53\%) of the people living with HIV, and HIV infection levels in one of Indonesia's provinces are 15 times greater than the national average [4]. As the Asian epidemics mature, HIV is spreading more widely, in particular to the female partners of IDUs and the clients of sex workers [3,5]. IDU, paid sex, and MSM are the main methods of HIV transmission in the Asian epidemics [4,5,115,117].

Despite a relatively small HIV epidemic in Oceania, the number of people living with HIV in this region almost doubled between 2001 and 2009. However, the number of people newly infected with HIV has begun to decrease. The Oceania HIV epidemics are driven mainly by sexual transmission, with unprotected heterosexual intercourse being the main mode of transmission with MSM predominating in the smaller Pacific countries, Australia and New Zealand. In Papua New Guinea's epidemic, paid sex appears to be routine among mobile populations (such as migrant workers, transport workers, and military personnel). IDU is a minor factor in the epidemics in this region, except among the aboriginal people in Australia [3,5,115].

Interventions : Regions with concentrated epidemics need to tailor their HIV prevention efforts to suit the high risk groups that are driving the epidemic. Individual risk assessment to tailor appropriate packages is critical to restricting the spread of the virus. In addition to providing the standard prevention package (SPP) of HCT, STI treatment, condom promotion, optional MMC for men, and behavior change counseling, additional biomedical and structural interventions are needed (Figure 1, Table 3).

Men that have sex with men: The main risk of HIV acquisition in MSM remains unprotected receptive anal intercourse, which needs to remain the primary focus of interventions. Therefore condom promotion and the use of water-based lubricants remain the most vital intervention in preventing HIV transmission in MSM. Behavioral interventions, treatment of STIs, the provision of non-discriminatory VCT services and decriminalization of homosexuality are also important interventions in HIV prevention for MSM $[118,119]$. In addition, MSM will require SSP treatment for prevention, PrEP and access to appropriate health infrastructure.

Sex workers: Female sex workers should have access to SPP plus mandatory $100 \%$ condom use programs, interventions to reduce stigma and appropriate health infrastructure to access care. Should oral or vaginal PrEP be efficacious in women then this additional method should be added to the prevention arsenal. Although far fewer in number when compared to female sex workers, transsexuals and men also engage in sex work in diverse social and cultural settings. Evidence suggests that male sex work is not a phenomenon that is limited only to certain regions. Although there is limited information on male sex workers from developing countries, there have been substantial reports in various countries in Latin America, Asia and Africa, as well as in most Western countries. Male sex workers frequently report sexual contacts both with male and female partners, representing a potential for heterosexual and homosexual transmission [120].

Male and transgender sex workers (MTSW) in Sub-Saharan Africa often engage in sex work for financial reasons and are therefore at high risk of HIV infection. Criminalization of homosexuality and marginalization are the driving forces for underground male sex work and therefore make it increasingly difficult to access MTSW with HIV/ AIDS prevention initiatives. A study of male sex workers in Mombasa, 
Kenya found that less than $50 \%$ of male sex workers surveyed consistently used condoms with their male clients. Low condom use among MTSW is of concern because of the increased risk of HIV transmission associated with anal sex. Male sex workers are also found to have low condom use rates with their female clients [121]. In the Dominican Republic, male sex workers have been identified as a high risk group for HIV infection, due to the secret nature of their work and lack of prevention programmes. The driving force for male sex work in this region is high unemployment rates in rural areas leading to migration to urban areas, and the profitable sex tourism industry [122].

Injection drug users: IDUs will benefit from SPP, needle exchange programs, methadone treatment programs, treatment for prevention and PrEP. An additional structural intervention will be needed for non-discriminatory access to health care.

Mobile populations: Mobile populations will benefit from SPP plus interventions preventing them from participating in unsafe transactional sex (such as increased wages, decreased travel time, spouses accompanying mobile employees and work place counseling programs). These specific interventions will be dependent on cost, adequate infrastructure, human resources and non-discriminatory HIV prevention delivery.

\section{Regions with generalized epidemics}

HIV prevalence in West Africa remains comparatively low, with the adult HIV prevalence estimated at $2 \%$ or under in 12 countries in 2009 (Democratic Republic of the Congo, Gambia, Benin, Burkina Faso, Ghana, Liberia, Mali, Guinea, Niger, Senegal, Mauritania and Sierra Leone).

In countries in central Africa, HIV prevalence exceeds 2 percent only in Cameroon (5.3 percent), Côte d'Ivoire (3.4 percent), Gabon (5.2 percent), and Nigeria (3.6 percent). Although Senegal as a national HIV prevalence of $0.9 \%$, a high of $30 \%$ among commercial sex workers have been reported in one of its urban centers $[2,3]$.

HIV prevalence has either decreased or remained stable in many countries in East Africa. In this region, national epidemics vary from country to country with the main form of HIV transmission being heterosexual sex. Prevalence in Kenya, Tanzania, and Uganda exceeds five percent (6.3 percent, 6.2 percent, and 5.4 percent, respectively). Unprotected sex between MSM was linked to almost 20\% of new HIV infections in Senegal and 15\% in Kenya and Rwanda. Injecting drug use plays a part in some of the regions epidemics (Kenya, Mauritius, and the United Republic of Tanzania) although it is a relatively recent phenomenon [2,3] In Western, Central and Eastern Africa, paid sex remains an important factor in HIV transmission.

$32 \%$ of AIDS deaths have occurred in Southern Africa [1]. 34\% of the global HIV positive population in 2009 lived in 10 countries in Southern Africa. Southern Africa has approximately $40 \%$ of all women living with HIV. 5.6 million people were estimated to be living with HIV in South Africa in 2010, the highest in the world. Other southern African countries have shown a stabilizing or decline in HIV incidence numbers; the East Africa epidemics have decreased since 2000. A decline in HIV prevalence among young men and women has been shown in national surveys from five countries (Botswana, Tanzania, South Africa, Zimbabwe and Zambia) [4]. This has been due to reported sexual behavior changes such as postponement of sexual debut, reduction in casual relationships and consistent condom use in some of these countries [7]. Most sub-Saharan African HIV transmission is through heterosexual transmission, although paid sex is also prevalent in some countries $[2,5,63]$.

Interventions (Figure 1, Table 3): Appropriate HIV prevention packages for these high HIV prevalence and HIV incidence communities remain a challenge. Many studies undertaken in these settings suggest poor adherence to both behavioral and biomedical interventions $[123,124]$, with the exception of PMTCT programs which are showing great success [125]. Coupled with behavioral risks are structural risks of poverty, migrant labor system, high prevalence of violence and rape and overburdened health systems [126,127]. Provision of antiretroviral drugs (ARVs) PMTCT services has improved but remains much lower in West and Central Africa (23 percent coverage) compared to East and Southern Africa (68 percent coverage). Due in part to its large population size, Nigeria has the second largest HIV disease burden in the world, at 3.3 million, though prevalence is stable (3.6 percent) [2,3].

South Africa in particular, needs a comprehensive HIV prevention, treatment and care program which can be delivered at a community level, taking into consideration task shifting whereby nurses and other health workers are able to provide HIV treatment and care. In addition, coupled with the raging HIV epidemic is the parallel epidemic of tuberculosis (TB). The prevention intervention program should include the SPP, treatment as prevention (if economically possible), targeted oral and vaginal PrEP (when available in very high risk groups) and numerous structural interventions such as cash transfers, empowerment of women, and workplace interventions for migrant workers, etc. This is a tall order by any means; however it is imperative that appropriate programmatic interventions are developed urgently. With the high prevalence and incidence of both HIV and TB, it is difficult to single out individuals at high risk as defined in other regions. A family-centric holistic approach of a wellness program integrating HIV prevention, treatment, and care, together with other health care needs such as tuberculosis treatment and reproductive health care is required. The country has developed an HIV/AIDS strategic plan which is comprehensive in its integration of HIV/TB prevention, treatment and care [128]. However, the use of additional biomedical interventions will require a large amount of funding, adequate infrastructure, excessive monitoring of adherence and human capital.

Other southern African countries have shown a stabilizing or decline in HIV incidence numbers; the East Africa epidemics have decreased since 2000. A decline in HIV prevalence among young men and women has been shown in national surveys from five countries (Botswana, Tanzania, South Africa, Zimbabwe and Zambia) [4]. This has been due to reported sexual behavior changes such as postponement of sexual debut, reduction in casual relationships and consistent condom use in some of these countries [7].

\section{HIV Epidemiology and Prevention}

It is abundantly clear that the global epidemic differs by region as well as by population groups. Known prevention methods such as abstinence, male/female condoms, STI treatment and safe sex counseling have not been entirely successful to prevent the transmission of HIV due to various social, economic, cultural and biological reasons.

The search for new biomedical interventions has resulted in a flood of successes in recent years. These include MMC, use of oral PrEP, prevention in HIV-negative individuals, early initiation of ART in those found to be HIV infected and a proof of concept of an ARV-based vaginal gel. Given the complexity and variation of the HIV epidemic in various regions worldwide, the concept of "one size fits all" prevention package is less likely to be successful. Hence the 
recent call for combination prevention strategies tailored to specific HIV risk profiles identified within countries with either concentrated or generalized epidemics is the way forward. Each country needs to acknowledge and accept the driving force in their specific epidemics and develop and provide an appropriate package of intervention (Figure 1). The UNAIDS call for "know your epidemic and know your response" speaks specifically to this [129]. The SPP of HCT, condom promotion, safe sex counseling, STI treatment, and optional MMC should be universal. The SPP should be enhanced with appropriate and manageable biomedical and structural interventions. Each country needs to balance these interventions appropriate to the population targeted, putting policies in place to reduce stigma and creating an environment which reduces vulnerability and increased uptake of proven HIV prevention interventions. Many of the interventions will require cost-effective analysis, monitoring and reevaluation as well as sustainability.

Mathematical modeling has identified the impact of individual HIV prevention options on HIV incidence [130]; however there is also a need to identify the most cost-effective intervention. MMC is cheap, considering that it is a once-off procedure and the implication it has on averting future health burdens $[62,131,132]$. MMC can be made available whereas other biomedical interventions will require identification of particular risk profiles, regular HIV testing, extensive adherence counseling, monitoring of resistance, and identifying people with acute infection (who are likely to be highly infectious for the first five months) and treating them to suppress the viral load and therefore, infectiousness would have a significant impact on HIV incidence. Scaling up of SPP plus other biomedical interventions will be critical. The challenge is that unless people are being tested on a regular basis, we will not be able to identify them in a non-research setting. Community-wide education, acceptability, access and addressing cultural sensitivities, will be critical to uptake of combination HIV prevention options to curb the epidemic.

\section{Conclusion}

It is evident that the epidemiology of HIV varies globally with each region having an epidemic profile of either being concentrated or generalized. Putting appropriate HIV prevention packages in concentrated epidemics appears to be easier due to the availability of data of highly efficacious interventions appropriate for the population with this high risk profile.

Scaling up of SPP, use of oral PrEP in discordant couples and MSM, PMTCT, and needle exchange programs for IDUs may have an impact on the spread of HIV. Reducing new HIV infections in generalized epidemics is likely to prove more challenging and where highly efficacious combinatorial approach tailored to specific risk profiles are needed. Strategically targeting community HIV "hot spots" with prevention options may be one of the ways of containing the spread of HIV.

\section{References}

1. Merson MH, O'Malley J, Serwadda D, Apisuk C (2008) The history and challenge of HIV prevention. Lancet 372: 475-488.

2. Delpech V, Gahagan J (2009) The global epidemiology of HIV. Medicine 37: 317-320.

3. UNAIDS (2010) Report on the global AIDS epidemic 2010. Geneva: Joint United Nations Programme on HIVIAIDS.

4. UNAIDS, editor (2011) World AIDS Day Report. Geneva: Joint United Nations Programme on HIVIAIDS
5. Kilmarx PH (2009) Global epidemiology of HIV. Curr Opin HIV AIDS 4: 240-246.

6. Bingenheimer JB, Geronimus AT (2009) Behavioral Mechanisms in HIV Epidemiology and Prevention: Past, Present, and Future Roles. Stud Fam Plann 40: 187-204

7. Simon V, Ho DD, Abdool Karim Q (2006) HIVIAIDS epidemiology, pathogenesis, prevention, and treatment. Lancet 368: 489-504.

8. Group NCHSPT (2007) Sexually transmitted disease and HIV prevalence and risk factors in concentrated and generalized HIV epidemic settings. AIDS 21: S81-90.

9. Ghys PD, Brown T, Grassly N, Garnett G, Stanecki K, et al. (2004) The UNAIDS Estimation and Projection Package: a software package to estimate and project national HIV epidemics. Sex Transm Infect 80: i5-9.

10. Cohen MS, Hellmann N, Levy JA, Decock K, Lange J (2008) The spread, treatment, and prevention of HIV-1: evolution of a global pandemic. J Clin Invest 118: 1244-1254.

11. Mills S, Saidel T, Magnani R, Brown T (2004) Surveillance and modelling of HIV STI, and risk behaviours in concentrated HIV epidemics. Sex Transm Infect 80: ii57-62.

12. De Cock KM, Mbori-Ngacha D, Marum E (2002) Shadow on the continent: Public health and HIVIAIDS in Africa in the 21st century. Lancet 360: 67-72.

13. Bertozzi SM, Laga M, Bautista-Arredondo S, Coutinho A (2008) Making HIV prevention programmes work. Lancet 372: 831-844.

14. Walker N, Grassly NC, Garnett GP, Stanecki KA, Ghys PD (2004) Estimating the global burden of HIVIAIDS: what do we really know about the HIV pandemic? Lancet 363: 2180-2185.

15. Walker N, Garcia-Calleja JM, Heaton L, Asamoah-Odei E, Poumerol G, et al. (2001) Epidemiological analysis of the quality of HIV sero-surveillance in the world: how well do we track the epidemic? AIDS 15: 1545-1554.

16. Pisani E, Lazzari S, Walker N, Schwartländer B (2003) HIV surveillance: a global perspective. J Acquir Immune Defic Syndr 32: S3-11.

17. Brookmeyer R (2010) Measuring the HIVIAIDS epidemic: Approaches and challenges. Epidemiol Rev 32: 26-37.

18. Stover J, Bertozzi S, Gutierrez J-P, Walker N, Stanecki KA, et al. (2006) The global impact of scaling up HIVIAIDS prevention programs in low- and middleincome countries. Science 311: 1474-1476.

19. Grabbe KL, Menzies N, Taegtmeyer M, Emukule G, Angala P, et al. (2010) Increasing access to HIV counseling and testing through mobile services in Kenya: strategies, utilization, and cost-effectiveness. J Acquir Immune Defic Syndr 54: 317-323.

20. Padian NS, McCoy SI, Karim SSA, Hasen N, Kim J, et al. (2011) HIV prevention transformed: the new prevention research agenda. Lancet 378: 269-278.

21. Rotheram-Borus MJ, Swendeman D, Chovnick G (2009) The past, present and future of HIV prevention: integrating behavioral, biomedical, and structural intervention strategies for the next generation of HIV prevention. Annu Rev Clin Psychol 5: 143-167.

22. Marks G, Crepaz N, Senterfitt JW, Janssen RS (2005) Meta-analysis of highrisk sexual behavior in persons aware and unaware they are infected with HIV in the United States: implications for HIV prevention programs. J Acquir Immune Defic Syndr 39: 446-453.

23. Coates TJ, Grinstead OA, Gregorich SE, Sweat M, Kamenga M, et al. (2000) Efficacy of voluntary HIV-1 counselling and testing in individuals and couples in Kenya, Tanzania, and Trinidad: a randomised trial. Lancet 356: 103-112.

24. Kurth A, Celum C, Baeten J, Vermund S, Wasserheit J (2011) Combination HIV Prevention: Significance, Challenges, and Opportunities. Curr HIVIAIDS Rep 8: 62-72.

25. Liang TS, Erbelding E, Jacob CA, Wicker H, Christmyer C, et al. (2005) Rapid HIV testing of clients of a mobile STD/HIV clinic. AIDS Patient Care STDS 19: 253-257.

26. Glynn JR, Kayuni N, Floyd S, Banda E, Francis-Chizororo M, et al. (2010) Age at menarche, schooling, and sexual debut in northern Malawi. PLoS One 5: e15334. 
Citation: Ramjee G, Daniels B (2012) Targeted Combination HIV Prevention Packages to Halt the Global HIV Epidemic. J AIDS Clinic Res S4:002. doi:10.4172/2155-6113.S4-002

Page 12 of 14

27. Greenberg J, Magder L, Aral S (1992) Age at first coitus a marker for risky sexual behavior in women. Sex Transm Dis 19: 331-334.

28. Manning W, Longmore M, Giordano P (2000) The relationship context of contraceptive use at first intercourse. Fam Plann Perspect 32: 104-110.

29. Boileau C, Clark S, Assche S, Poulin M, Reniers G, et al. (2009) Sexual and marital trajectories and HIV infection among ever-married women in rural Malawi. Sex Transm Infect 85: i27-i33.

30. Pettifor AE, Rees HV, Kleinschmidt I, Steffenson AE, MacPhail C, et al. (2005) Young people's sexual health in South Africa: HIV prevalence and sexua behaviors from a nationally representative household survey. AIDS 19: 15251534.

31. Wand H, Whitaker C, Ramjee G (2011) Geoadditive models to assess spatial variation of HIV infections among women in local communities of Durban. Int $J$ Health Geogr 10: 28.

32. Padian N, van der Straten A, Ramjee G, Chipato T, de Bruyn G, et al. (2007) Diaphragm and lubricant gel for prevention of HIV acquisition in southern African women: A randomised controlled trial. Lancet 370: 251-261.

33. Laga M, Schwärtlander B, Pisani E, Sow PS, Caraël M (2001) To stem HIV in Africa, prevent transmission to young women. AIDS 15: 931-934.

34. Asiimwe-Okiror G, Opio A, Musinguzi J, Madraa E, Tembo G, et al. (1997) Change in sexual behaviour and decline in HIV infection among young pregnant women in urban Uganda. AIDS 11: 1757-1763.

35. Medley A, Kennedy C, O'Reilly K, Sweat M (2009) Effectiveness of peer education interventions for HIV prevention in developing countries: a systematic review and meta-analysis. AIDS Educ Prev 21: 181-206.

36. Fung I, Guinness L, Vickerman P, Watts C, Vannela G, et al. (2007) Modelling the impact and cost-effectiveness of the HIV intervention programme amongst commercial sex workers in Ahmedabad, Gujarat, India. BMC Public Health 7: 195.

37. Luchters S, Chersich M, Rinyiru A, Barasa MS, King'ola N, et al. (2008) Impact of five years of peer-mediated interventions on sexual behavior and sexually transmitted infections among female sex workers in Mombasa, Kenya. BMC Public Health 8: 143

38. Sutcliffe C, Srirojn B, Latkin CA, Aramratanna A, Sherman SG, et al. (2009) Evaluation of a peer network intervention trial among young methamphetamine users in Chiang Mai, Thailand. Soc Sci Med (1982) 68: 69-79.

39. Jewkes R, Nduna M, Levin J, Jama N, Dunkle K, et al. (2008) Impact of Stepping Stones on incidence of HIV and HSV-2 and sexual behaviour in rural South Africa: Cluster randomised controlled trial. BMJ 337: a506.

40. Bertrand JT, O'Reilly K, Denison J, Anhang R, Sweat M (2006) Systematic review of the effectiveness of mass communication programs to change HIV AIDS-related behaviors in developing countries. Health Educ Res 21: 567-597.

41. Kuhlmann AKS, Kraft JM, Galavotti C, Creek TL, Mooki M, et al. (2008) Radio role models for the prevention of mother-to-child transmission of HIV and HIV testing among pregnant women in Botswana. Health promot Int 23: 260-268.

42. Keating J, Meekers D, Adewuyi A (2006) Assessing effects of a media campaign on HIVIAIDS awareness and prevention in Nigeria: results from the VISION Project. BMC Public Health 6: 123.

43. Van Rossem R, Meekers D (2007) The reach and impact of social marketing and reproductive health communication campaigns in Zambia. BMC Public Health 7: 352

44. Halperin D, Epstein H (2007) Why is HIV prevalence so severe in southern Africa? The role of multiple concurrent partnerships and lack of male circumcision: Implications for AIDS prevention. The Southern African Journal of HIV Medicine 8: 19-25

45. Mah TL, Halperin DT (2010) Concurrent sexual partnerships and the HIV epidemics in Africa: evidence to move forward. AIDS Behav 14: 11-16.

46. Mishra V, Hong R, Assche S, Barrere B (2009) The role of partner reduction and partner faithfulness in HIV prevention in sub-Saharan Africa: Evidence from Cameroon, Rwanda, Uganda, and Zimbabwe. DHS Working Paper.

47. Potts M, Halperin DT, Kirby D, Swidler A, Marseille E, et al. (2008) Reassessing HIV prevention. Science 320: 749-750.

48. Shelton JD, Halperin DT, Nantulya V, Potts M, Gayle HD, et al. (2004) Partner reduction is crucial for balanced "ABC" approach to HIV prevention. BMJ 328 : 891-893.
49. Gupta GR, Parkhurst JO, Ogden JA, Aggleton P, Mahal A (2008) Structural approaches to HIV prevention. Lancet 372: 764-775.

50. Slutkin G, Okware S, Naamara W, Sutherland D, Flanagan D, et al. (2006) How Uganda reversed its HIV epidemic. AIDS Behav 10: 351-360.

51. Parker RG, Easton D, Klein CH (2000) Structural barriers and facilitators in HIV prevention: a review of international research. AIDS 14: S22-32.

52. Dworkin S, Blankenship K (2009) Microfinance and HIVIAIDS Prevention: Assessing its Promise and Limitations. AIDS Behav 13: 462-469.

53. Lurie M, Williams B, Zuma K, Mkaya-Mwamburi D, Garnett G, et al. (2003) The impact of migration on HIV-1 transmission in South Africa: A study of migrant and nonmigrant men and their partners. Sexy Transm Dis 30: 149-156.

54. Ramjee G, Gouws E (2002) Prevalence of HIV among truck drivers visiting sex workers in KwaZulu-Natal, South Africa. Sex Transm Dis 29: 44-49.

55. Pulerwitz J, Michaelis A, Weiss E, Brown L, Mahendra V (2010) Reducing HIVrelated stigma: Lessons learned from Horizons research and programs. Public Health Rep 125: 272-281.

56. McIntyre JA (2010) The need for HIV prevention interventions for men who have sex with men in Africa. Sex Transm Infect 86: 82-83.

57. Khuât T, Ashburn K, Pulerwitz J, Ogden J, Nyblade L (2008) Improving hospital-based quality of care in Vietnam by reducing HIV-related stigma and discrimination. Washington DC: USAID, ISDS, ICRW, PEPFAR, Path. Horizons The Population Council.

58. Sawires SR, Dworkin SL, Fiamma A, Peacock D, Szekeres G, et al. (2007) Male circumcision and HIVIAIDS: challenges and opportunities. Lancet 369: 708-713.

59. Weiss HA, Quigley MA, Hayes RJ (2000) Male circumcision and risk of HIV infection in sub-Saharan Africa: a systematic review and meta-analysis. AIDS 14: 2361-2370.

60. Auvert B, Taljaard D, Lagarde E, Sobngwi-Tambekou J, Sitta R, et al. (2005) Randomized, controlled intervention trial of male circumcision for reduction of HIV infection risk: The ANRS 1265 trial. PLoS Med 2: e298.

61. Bailey RC, Moses S, Parker CB, Agot K, Maclean I, et al. (2007) Male circumcision for HIV prevention in young men in Kisumu, Kenya: A randomised controlled trial. Lancet 369: 643-656.

62. Gray RH, Kigozi G, Serwadda D, Makumbi F, Watya S, et al. (2007) Male circumcision for HIV prevention in men in Rakai, Uganda: A randomised trial. Lancet 369: 657-666.

63. Buchbinder S (2010) HIV epidemiology, testing strategies, and prevention interventions. Top HIV Med 18: 38-44.

64. 64. Millett GA, Flores SA, Marks G, Reed JB, Herbst JH (2008) Circumcision status and risk of HIV and sexually transmitted infections among men who have sex with men. JAMA 300: 1674-1684.

65. Mustanski BS, Newcomb ME, Du Bois SN, Garcia SC, Grov C (2011) HIV in Young Men Who Have Sex with Men: A Review of Epidemiology, Risk and Protective Factors, and Interventions. J Sex Res 48: 218-253.

66. Curran K, Njeuhmeli E, Mirelman A, Dickson K, Adamu T, et al. (2011) Voluntary Medical Male Circumcision: Strategies for Meeting the Human Resource Needs of Scale-Up in Southern and Eastern Africa. PLoS Med 8: e1001129.

67. Wambura M, Mwanga J, Mosha J, Mshana G, Mosha F, et al. (2011) Acceptability of medical male circumcision in the traditionally circumcising communities in Northern Tanzania. BMC Public Health 11: 373.

68. Herman-Roloff A, Otieno N, Agot K, Ndinya-Achola J, Bailey RC (2011) Acceptability of Medical Male Circumcision Among Uncircumcised Men in Kenya One Year After the Launch of the National Male Circumcision Program. PLoS One 6: e19814.

69. Wilcken A, Miiro-Nakayima F, Hizaamu R, Keil T, Balaba-Byansi D (2010) Male circumcision for HIV prevention-a cross-sectional study on awareness among young people and adults in rural Uganda. BMC Public Health 10: 209.

70. Gwandure C (2012) The ethical concerns of using medical male circumcision in HIV prevention in sub-Saharan Africa. South African Journal of Bioethics and Law 4: 89-94.

71. Golombok S, Harding R, Sheldon J (2001) An evaluation of a thicker versus a standard condom with gay men. AIDS 15: 245-250. 
Citation: Ramjee G, Daniels B (2012) Targeted Combination HIV Prevention Packages to Halt the Global HIV Epidemic. J AIDS Clinic Res S4:002. doi:10.4172/2155-6113.S4-002

Page 13 of 14

72. Baron S, Poast J, Nguyen D, Cloyd MW (2001) Practical prevention of vaginal and rectal transmission of HIV by adapting the oral defense: use of commercial lubricants. AIDS Res Hum Retroviruses 17: 997-1002.

73. Grosskurth H, Todd J, Mwijarubi E, Mayaud P, Nicoll A, et al. (1995) Impact of improved treatment of sexually transmitted diseases on HIV infection in rural Tanzania: Randomised controlled trial. Lancet 346: 530-536.

74. Grosskurth H, Gray R, Hayes R, Mabey D, Wawer M (2000) Control of sexually transmitted diseases for HIV-1 prevention: Understanding the implications of the Mwanza and Rakai trials. Lancet 355: 1981-1987.

75. Lagakos SW, Gable AR (2008) Challenges to HIV prevention -- seeking effective measures in the absence of a vaccine. N Engl J Med 358: 1543-1545.

76. del Mar Pujades Rodríguez M, Obasi A, Mosha F, Todd J, Brown D, et al. (2002) Herpes simplex virus type 2 infection increases HIV incidence: A prospective study in rural Tanzania. AIDS 16: 451-462.

77. Freeman E, Weiss H, Glynn J, Cross P, Whitworth J, et al. (2006) Herpes simplex virus 2 infection increases HIV acquisition in men and women: Systematic review and meta-analysis of longitudinal studies. AIDS 20: 73-83.

78. Celum C, Wald A, Hughes J, Sanchez J, Reid S, et al. (2008) Effect of aciclovir on HIV-1 acquisition in herpes simplex virus 2 seropositive women and men who have sex with men: A randomised, double-blind, placebo-controlled trial. The Lancet 371: 2109-2119.

79. Watson-Jones D, Weiss HA, Rusizoka M, Changalucha J, Baisley K, et al. (2008) Effect of herpes simplex suppression on incidence of HIV among women in Tanzania. N Engl J Med 358: 1560-1571.

80. Celum C, Wald A, Lingappa JR, Magaret AS, Wang RS, et al. (2010) Acyclovir and transmission of HIV-1 from persons infected with HIV-1 and HSV-2. N Engl J Med 362: 427-439.

81. Organization WH (2009) Rapid advice: use of antiretroviral drugs for treating pregnant women and preventing HIV infection in infants. Geneva: WHO.

82. Rabkin M, El-Sadr WM (2003) Saving Mothers, Saving Families: The MTCTPlus Initiative: Case Study: World Health Organization.

83. Dao H, Mofenson LM, Ekpini R, Gilks CF, Barnhart M, et al. (2007) International recommendations on antiretroviral drugs for treatment of HIV-infected women and prevention of mother-to-child HIV transmission in resource-limited settings: 2006 update. Am J Obstet Gynecol 197: S42-55.

84. Mathers BM, Degenhardt L, Ali H, Wiessing L, Hickman M, et al. (2010) HIV prevention, treatment, and care services for people who inject drugs: a systematic review of global, regional, and national coverage. The Lancet 375 : 1014-1028.

85. Degenhardt L, Mathers B, Vickerman P, Rhodes T, Latkin C, et al. (2010) Prevention of HIV infection for people who inject drugs: why individual, structural, and combination approaches are needed. Lancet 376: 285-301.

86. Wodak A, Cooney A (2005) Effectiveness of sterile needle and syringe programmes. The International Journal on Drug Policy 16: 31-44.

87. Vlahov D, Robertson AM, Strathdee SA (2010) Prevention of HIV infection among injection drug users in resource-limited settings. Clin Infect Dis 50: S114-121.

88. Cohen MS, Chen YQ, McCauley M, Gamble T, Hosseinipour MC, et al. (2011) Prevention of HIV-1 infection with early antiretroviral therapy. N Engl J Med 365: 493-505.

89. Dieffenbach CW, Fauci AS (2009) Universal voluntary testing and treatment for prevention of HIV transmission. JAMA 301: 2380-2382.

90. Mayer KH, Venkatesh KK (2010) Antiretroviral therapy as HIV prevention Status and prospects. Am J Public Health 100: 1867-1876.

91. García-Lerma JG, Paxton L, Kilmarx PH, Heneine W (2010) Oral pre-exposure prophylaxis for HIV prevention. Trends Pharmacol Sci 31: 74-81.

92. Peterson L, Taylor D, Roddy R, Belai G, Phillips P, et al. (2007) Tenofovir disoproxil fumarate for prevention of HIV infection in women: a phase 2, doubleblind, randomized, placebo-controlled trial. PLoS Clin Trials 2: e27.

93. Grant RM, Lama JR, Anderson PL, McMahan V, Liu AY, et al. (2010) Preexposure chemoprophylaxis for HIV prevention in men who have sex with men. N Engl J Med 363: 2587-2599.
94. Partners in PreP.

95. Partners PrEP study demonstrates that PrEP significantly reduces HIV risk: key messages.

96. TDF2 study of pre-exposure prophylaxis (PrEP) among heterosexual men and women in Botswana: key facts KEY FACTS.

97. FEM-PrEP June 2011 Update.

98. VOICE prevention trial continues, but researchers suspend oral tenofovir arm because of futility.

99. van Damme L, Ramjee G, Alary M, Vuylsteke B, Chandeying V, et al. (2002) Effectiveness of COL-1492, a nonoxynol-9 vaginal gel, on HIV-1 transmission in female sex workers: A randomised controlled trial. Lancet 360: 971-977.

100. Feldblum P, Adeiga A, Bakare R, Wevill S, Lendvay A, et al. (2008) SAVVY vaginal gel $(\mathrm{C} 31 \mathrm{G})$ for prevention of HIV infection: A randomized controlled trial in Nigeria. PLoS One 3: e1474.

101.Peterson L, Nanda K, Opoku BK, Ampofo WK, Owusu-Amoako M, et al. (2007) SAVVY® (C31G) gel for prevention of HIV infection in women: A phase 3 , double-blind, randomized, placebo-controlled trial in Ghana. PLoS One 2: e1312.

102. Abdool Karim SS, Richardson BA, Ramjee G, Hoffman IF, Chirenje ZM, et al. (2011) Safety and effectiveness of BufferGel and 0.5\% PRO2000 gel for the prevention of HIV infection in women. AIDS 25: 957-966.

103.Skoler-Karpoff S, Ramjee G, Ahmed K, Altini L, Plagianos M, et al. (2008) Efficacy of Carraguard for prevention of HIV infection in women in South Africa: A randomised, double-blind, placebo-controlled trial. The Lancet 372 : 1977-1987.

104.van Damme L, Govinden R, Mirembe F, Guédou F, Solomon S, et al. (2008) Lack of effectiveness of cellulose sulfate gel for the prevention of vaginal HIV transmission. N Engl J Med 359: 463-472.

105. CONRAD (2007) Phase III trials of cellulose sulfate microbicide for HIV prevention closed [press release].

106. McCormack S, Ramjee G, Kamali A, Rees H, Crook AM, et al. (2010) PRO2000 vaginal gel for prevention of HIV-1 infection (Microbicides Development Programme 301): A phase 3, randomised, double-blind, parallel-group trial. Lancet 376: 1329-1337.

107. Abdool Karim Q, Abdool Karim SS, Frohlich JA, Grobler AC, Baxter C, et al (2010) Effectiveness and safety of tenofovir gel, an antiretroviral microbicide, for the prevention of HIV infection in women. Science 329: 1168-1174.

108. VOICE HIV Prevention Trial Discontinues Tenofovir Gel Arm for Futility.

109.Gray GE, Allen M, Moodie Z, Churchyard G, Bekker LG, et al. (2011) Safety and efficacy of the HVTN 503/Phambili Study of a clade-B-based HIV-1 vaccine in South Africa: A double-blind, randomised, placebo-controlled testof-concept phase 2b study. Lancet Infect Dis 11: 507-515.

110. Rerks-Ngarm S, Pitisuttithum P, Nitayaphan S, Kaewkungwal J, Chiu J, et al. (2009) Vaccination with ALVAC and AIDSVAX to prevent HIV-1 infection in Thailand. N Engl J Med 361: 2209-2220.

111. Pitisuttithum P, Gilbert P, Gurwith M, Heyward W, Martin M, et al. (2006) Randomized, double-blind, placebo-controlled efficacy trial of a bivalen recombinant glycoprotein $120 \mathrm{HIV}-1$ vaccine among injection drug users in Bangkok, Thailand. J Infect Dis 194: 1661-1671.

112. Buchbinder S, Mehrotra D, Duerr A, Fitzgerald D, Mogg R, et al. (2008) Efficacy assessment of a cell-mediated immunity HIV-1 vaccine (the Step Study): A double-blind, randomised, placebo-controlled, test-of-concept trial. Lancet 372: 1881-1893.

113. Flynn NM, Forthal DN, Harro CD, Judson FN, Mayer KH, et al. (2005) Placebocontrolled phase 3 trial of a recombinant glycoprotein 120 vaccine to prevent HIV-1 infection. J Infect Dis 191: 654-665.

114. Ongoing and Planned Trials of Preventive HIVIAIDS Vaccines, January 2012

115. Quinn TC (2008) HIV epidemiology and the effects of antiviral therapy on longterm consequences. AIDS 22: S7-12.

116. Mayer KH, Beyrer C (2007) HIV Epidemiology Update and Transmission Factors: Risks and Risk Contexts-16th International AIDS Conference Epidemiology Plenary. Clin Infect Dis 44: 981-987. 
Citation: Ramjee G, Daniels B (2012) Targeted Combination HIV Prevention Packages to Halt the Global HIV Epidemic. J AIDS Clinic Res S4:002. doi:10.4172/2155-6113.S4-002

Page 14 of 14

117. Kandwal R, Garg PK, Garg RD (2009) Health GIS and HIVIAIDS studies: Perspective and retrospective. J Biomed Inform 42: 748-755.

118. Beyrer C (2010) Global prevention of HIV infection for neglected populations: men who have sex with men. Clin Infect Dis 50: S108-113.

119. van Griensven F, de Lind van Wijngaarden JW (2010) A review of the epidemiology of HIV infection and prevention responses among MSM in Asia. AIDS 24: S30-40.

120. Joint United Nations Programme on HIV A (2002) Sex Work and HIV AIDS: UNAIDS Technical Update: UNAIDS.

121. KENYA: Bisexual male sex workers run big risks.

122. Padilla M (2007) Caribbean pleasure industry: tourism, sexuality, and AIDS in the Dominican Republic: University of Chicago Press.

123.van der Straten A, Shiboski S, Montgomery ET, Moore J, De Bruyn G, et al. (2009) Patterns and predictors of adherence to diaphragm use in a phase III trial in sub-Saharan Africa: A trajectory analysis. J Acquir Immune Defic Syndr 50: 419-426.

124. Ramjee G, Coumi N, Dladla-Qwabe N, Ganesh S, Gappoo S, et al. (2010) Experiences in conducting multiple community-based HIV prevention trials among women in KwaZulu-Natal, South Africa. AIDS Res Ther 7: 10.

125. Horwood C, Haskins L, Vermaak K, Phakathi S, Subbaye R, et al. (2010) Prevention of mother to child transmission of HIV (PMTCT) programme in
KwaZulu-Natal, South Africa: an evaluation of PMTCT implementation and integration into routine maternal, child and women's health services. Trop Med Int Health.

126. Chopra M, Lawn JE, Sanders D, Barron P, Karim SSA, et al. (2009) Achieving the health Millennium Development Goals for South Africa: challenges and priorities. The Lancet 374: 1023-1031.

127. Seedat M, Van Niekerk A, Jewkes R, Suffla S, Ratele K (2009) Violence and injuries in South Africa: Prioritising an agenda for prevention. Lancet 374: 1011-1022.

128. Department of Health (2007) HIV \& AIDS and STI Strategic Plan for South Africa 2007-2011. National Department of Health.

129. Know your Epidemic and your Current Response.

130. Hallett TB, White PJ, Garnett GP (2007) Appropriate evaluation of HIV prevention interventions: from experiment to full-scale implementation. Sex Transm Infect 83: i55-60.

131. Njeuhmeli E, Forsythe S, Reed J, Opuni M, Bollinger L, et al. (2011) Voluntary medical male circumcision: modeling the impact and cost of expanding male circumcision for HIV prevention in eastern and southern Africa. PLoS Med 8: e1001132.

132. Auvert B, Marseille E, Korenromp EL, Lloyd-Smith J, Sitta R, et al. (2008) Estimating the Resources Needed and Savings Anticipated from Roll-Out of Adult Male Circumcision in Sub-Saharan Africa. PLoS One 3: e2679.
This article was originally published in a special issue, Epidemiology and Prevention: HIV handled by Editor(s). Han-zhu Qian, VVanderbilt University School of Medicinem, USA. 